$\underline{\text { Review Article }}$

\title{
VITAMIN A DERIVATIVES USE IN THE TREATMENT OF SKIN CONDITIONS
}

\author{
MOHAMMED AL-ABADIEa, FARIS OUMEISHa, MOHAMMED AL-RUBAYEa, SHAHID RAFIQ ${ }^{\mathrm{b}}$, PATRICK ANTHONY \\ BALLc, HANA MORRISSEYc
}

aDepartment of Dermatology Royal Wolverhampton, NHS Trust, Wolverhampton, United Kingdom, bWolverhampton Clinical Commetioning Group, Wolverhampton, United Kingdom, cSchool of Pharmacy, University of Wolverhampton, Wolverhampton, United Kingdom Email: hana.morrissey@wlv.ac.uk

Received: 13 Jul 2020, Revised and Accepted: 11 Sep 2020

\begin{abstract}
Retinoids are used to treat various skin diseases. They add valuable impact of when used early in the treatment of dermatological conditions. Overall vitamin A derivatives are underused, with isotretinoin is the most used. This paper aims to develop prescribers' knowledge about their benefits, to improve their usability and aids in alleviating patient concerns to improve therapeutic outcomes in dermatological conditions. In acne vulgaris, adapalene gel and tretinoin cream showed equal efficacy. In psoriasis the combination of acitretin and PUVA was superior to PUVA alone. Acitretin showed a reduction of $41 \%$ in the Nail Psoriasis Severity Index and similar efficacy to potent steroids and calcipotriol. In chronic hand eczema, alitretinoin showed 50\% improvement in patient's refractory to steroid treatment. In photoaging and aging, retinoids were shown to increase the synthesis and decrease the degradation rate of collagen and hyaluronate, reducing the impact of aging. In rosacea, topical and systemic isotretinoin showed complete remission in $24 \%$ of the patients compared to only $14 \%$ with antibiotics (metronidazole and doxycycline). In lichen planus, isotretinoin demonstrated clinical and histopathological efficacy. In cutaneous T-cell lymphoma, bexarotene used alone or with PUVA or narrow band UVB, showed a response between $80.0 \%$ to $84.0 \%$. Lastly in Kaposi sarcoma alitretinoin gel showed superiority to all other agents and better tolerance. This review highlights the benefit of timely use of vitamin A derivatives to encourage wider use.
\end{abstract}

Keywords: Isotretinoin, Vitamin A, Acne Vulgaris, Psoriasis, Photoaging and aging

(C) 2020 The Authors. Published by Innovare Academic Sciences Pvt Ltd. This is an open access article under the CC BY license (http://creativecommons.org/licenses/by/4.0/) DOI: http://dx.doi.org/10.22159/ijcpr.2020v12i6.40294. Journal homepage: https://innovareacademics.in/journals/index.php/ijcpr

\section{INTRODUCTION}

Vitamin A has both natural and synthetic derivatives, collectively known as retinoids. Retinoids play an important role in embryogenesis (including both cell growth and differentiation) and in cellular inflammation. They exert their actions through binding to different retinoid-binding proteins and to retinoid nuclear receptors. Retinoids are widely used to treat a range of dermatological conditions due their effects on the proliferation of keratinocytes and epidermal differentiation [1]. The retinoids used to treat various skin diseases are divided into three generations. 'First generation' are the naturally occurring non-aromatic retinoids which include: Vitamin A (all-trans retinol), tretinoin (all-trans retinoic acid), isotretinoin (13-cis retinoic acid) and alitretinoin (9-cis retinoic acid). 'Second-generation' are the monoaromatic derivatives, which include: etretinate and its biologically active metabolite acitretin. 'Third generation' are the polyaromatic derivatives which include: adapalene, bexarotene and tazarotene [1].

\section{Purpose of the review}

This review aims to highlight the positive impact of the use and/or early use of vitamin A derivatives, both natural and synthetic, in the treatment of dermatological conditions. In the authors' local areas, during the past $3 \mathrm{y}$, Vitamin A derivatives were underused (table 1), with only isotretinoin been used. This paper aims to develop prescribers' knowledge about their benefits to improve their usability and aids in patients scares reductions as one of the main goals of dermatological conditions therapeutics outcomes.

Table 1: Cost of Isotretinoin provided by one CCG in west midlands with a population of 210,319

\begin{tabular}{|c|c|c|c|c|c|}
\hline Costs & 2017 & 2018 & 2019 & 2020 & TOTAL \\
\hline Isotretinoin $0.05 \%$ /Erythromycin $2 \%$ gel & $£ 452.16$ & $£ 557.83$ & $£ 514.16$ & $£ 41.74$ & $£ 1,565.89$ \\
\hline Total & $£ 452.16$ & $£ 557.83$ & $£ 514.16$ & $£ 41.74$ & $£ 1,565.89$ \\
\hline Items & 2017 & 2018 & 2019 & 2020 & TOTAL \\
\hline Isotretinoin $5 \mathrm{mg}$ capsules & 53 & 57 & 56 & 5 & $£ 171.00$ \\
\hline Total & 53 & 57 & 56 & 5 & 171 \\
\hline
\end{tabular}

\section{Mode of action}

Retinoids exert their effects by binding to retinoid-binding proteins, or activating, the nuclear retinoic acid receptors (RAR) and retinoid $X$ receptors (RXR). Each of these receptors are composed of 3 isotypes: $\alpha, \beta$ and $\gamma$. Both types of receptors exist together as a dimer. The retinoids exhibit different binding affinities and characteristics to both types of receptors [2].

\section{Side effects}

The side effects of systemic retinoids are dose-dependent and resemble those seen in hypervitaminosis $\mathrm{A}$. The most common are mucocutaneous, with chelitis being the earliest and most frequently observed side effect [3]. Other mucocutaneous effects include dryness in the oral and nasal mucosa (which might lead to epistaxis), dryness of the eyes, hair loss and nail fragility. Musculoskeletal effects include bone pain, arthralgias and myalgias. Hyperlipidaemia is caused by increased cholesterol and triglyceride levels and a reduction in HDL levels. Teratogenicity remains the most concerning side effect caused by retinoids. The FDA considers oral retinoids to be category $\mathrm{X}$ as they may cause foetal malformation by their effects on the developing central nervous system, heart, ear and thymus. Transient elevation in transaminase levels has been reported in $20 \%$ of patients, especially those treated with acitretin, and less 
frequently those treated with isotretinoin and bexarotene [4]. In terms of psychiatric effects, opposing opinions exist between dermatologists and psychiatrists on the effect of isotretinoin in the occurrence of mood disorders especially depression and this topic has been heavily debated. Bremner et al. (2012) have demonstrated a link between isotretinoin and depression [5]. They provided evidence from case reports in the literature, temporal association, challenge-re-challenge studies, dose-response, biological plausibility and class effect. On the other hand many dermatological studies have suggested that the presence of acne itself causes depression and treating acne with isotretinoin is one way to treat depression, since there will be improved self-image and an overall more positive behaviour by the affected person [6]. Neurological effects are rare although symptoms of pseudotumor cerebi may occasionally occur.

\section{Therapeutic uses}

\section{Acne vulgaris}

The US Food and Drug Administration (FDA) approved the medical use of isotretinoin in 1982. The European Directive for prescribing systemic isotretinoin for acne vulgaris stated in 2006, that isotretinoin should only be used to treat severe acne (nodular, conglobata) that has not responded or is not responding to appropriate antibiotics and topical therapy [7]. Isotretinoin (13-cisretinoic acid) has anti-inflammatory properties, decreases hyperkeratinisation which will reduce comedone formation, reduces production of sebum and reduces colonization of the pilosebaceous duct with Propionibacterium acnes [8]. P. acnes induce the immune response in affected patients, which results in the inflammatory response of acne [9]. Isotretinoin reduces Toll-like receptor-2 (TLR2) expression in monocytes which will result in decreasing inflammatory cytokine production in response to P. acnes. It was found that this effect continues for 6 mo after completion of therapy which indicates that the therapeutic effects of isotretinoin may be due to TLR-2 modulation [10].

The topical retinoids approved for acne treatment include tretinoin, adapalene and tazarotene. Tazorotene is currently only approved in the US. Topical retinoids are effective in treating mild to moderate acne [11]. They exert an anti-inflammatory effect in addition to preventing the formation of micro-comedones, the precursor lesion of comedones. Since each retinoid binds to different subtypes of the retinoic acid receptors, this leads to differences in both efficacy and tolerability. Tretinoin binds to all 3 subtypes $(\alpha, \beta$ and $\gamma)$ of retinoic acid receptors, while adapalene and tazorotene only selectively bind to $\beta$ and $\gamma$ subtypes. Women of childbearing age should be counselled on topical retinoid therapy since Tazorotene is pregnancy category $\mathrm{X}$, while adapalene and tretinoin are category C [12]. In a study comparing Tazarotene $0.1 \%$ gel to tretinoin $0.1 \%$ microsponge, tazarotene was found to have greater efficacy and comparable tolerability to tretinoin in treating mild-to-moderate inflammatory facial acne vulgaris [13]. In a clinical trial comparing efficacy and safety of adapalene gel $0.1 \%$ and tretinoin cream $0.05 \%$ in patients with mild-moderate acne, adapalene gel had better tolerability and equivalent efficacy compared to tretinoin cream over a 10week period [14].

\section{Psoriasis}

The only systemic retinoid that has been approved by the FDA for psoriasis is acitretin. Acitretin exerts its effects by binding to all subtypes $(\alpha, \beta$ and $\gamma)$ of RAR and RXR receptors, which result in reduction of the proliferation of epidermal keratinocytes. This leads to a decrease in erythema, desquamation and thickness of the lesion [15]. Acitretin is indicated in the treatment of pustular psoriasis, erythrodermic psoriasis and severe psoriasis that cannot be managed by topical treatment or phototherapy [16]. It was found in a randomized, double-blind, placebo-controlled study that the combination of acitretin and PUVA in treating severe psoriasis was superior to PUVA alone, achieving a $75 \%$ decrease in Psoriasis Severity Index and resulting in complete remission [17]. Tosti el al. (2009) evaluated the efficacy of acitretin in treating isolated nail psoriasis over a period of 6 mo. Their results showed a reduction of $41 \%$ in the Nail Psoriasis Severity Index (NAPSI) score and they concluded that the reduction in NAPSI score achieved with low dose acitretin treatment is comparable to that achieved with the biologics
[18]. In a study conducted on 10 patients with severe psoriasis receiving acitretin treatment daily, four patients had plasma etretinate (the teratogenic ethyl ester of acitretin) in teratogenic levels, this was linked to alcohol consumption which leads to reesterification of acitretin to etretinate. For this reason, any female of childbearing age receiving acitretin should be advised to continue using contraception for a period of $3 \mathrm{y}$, since etretinate was found to accumulate in the adipose tissue for a period of 18 mo post cessation of the treatment $[19,20]$.

Tazorotene is the only topical retinoid approved for the treatment of psoriasis. In the UK tazorotene is indicated for treating mild to moderate plaque psoriasis affecting up to $10 \%$ of the surface area of the body, while in the US it is indicated in treating stable plaque psoriasis affecting up to $20 \%$ of the surface area of the body [16]. Tazorotene is metabolized to tazarotenic acid its active metabolite by estrases in the skin. It is thought that tazorotene modulates proliferation and differentiation of keratinocytes and also regulates inflammation [21]. Mason et al. conducted a meta-analysis of topical preparations for the treatment of psoriasis, which reported tazoretene to have clinical efficacy similar to potent steroids and calcipotriol [22].

\section{Chronic hand eczema}

Alitretinoin was approved in the UK in 2008 for treating chronic hand eczema that is refractory to topical steroid treatment in patients who are $>18 \mathrm{y}$ old. It exerts its effects by binding to both RAR and RXR receptors. In a randomized controlled study of patients receiving oral alitretinoin once daily for up to $24 \mathrm{w}$, there was almost $50 \%$ improvement in patients with chronic hand eczema that was refractory to standard therapy $[23,24]$.

\section{Photoaging and aging}

Retinoids in clinical trials have been shown to decrease the levels of Matrix Metallopeptidases (MMP) that are responsible for catalysing the degradation of collagen and elastin. They have also been demonstrated to increase the thickness of the epidermis which in turn will reduce the appearance of fine wrinkles [25]. The chemical structures of retinoids allow them to absorb UV radiation and trap free radicals, enabling them to protect cellular proteins from photodegradation and oxidative stress. Retinoids bind to nuclear receptors and modulate the expression of the genes involved in cellular proliferation and differentiation. Retinoids can increase the synthesis and decrease the degradation rate of collagen and hyaluronate; two important components of the dermis that are frequently altered and decreased by the process of aging [26].

\section{Rosacea}

Topical and systemic isotretinoin can be used 'off-label' (outside of the licensed indications) in the treatment of rosacea. In a study conducted by Altinyazar et al. (2005) to evaluate the efficacy of topical adapalene gel $(0.1 \%)$ and topical metronidazole gel $(0.75 \%)$ in the treatment of papulopustular rosacea. The study showed a significant reduction in the total number of inflammatory lesions in the patients treated with adapalene, but there was no improvement in the scores of erythema or telangiectasia in the same group. The group treated with metronidazole showed improvement in the erythema score [27]. In a placebo-controlled, randomized clinical study conducted over a period of $12 \mathrm{w}$ for 573 patients with rosacea subtype II and III, patients either received isotretinoin in 3 different dosages, doxycycline or placebo. The results showed a $90 \%$ reduction of lesions in the $0.3 \mathrm{mg} / \mathrm{kg}$ isotretinoin group while the doxycycline group demonstrated $83 \%$ reduction in the lesions. Complete remission was achieved in $24 \%$ of the patients treated with $0.3 \mathrm{mg} / \mathrm{kg}$ isotretinoin compared to only $14 \%$ achieved in the doxycycline group. Thus, the study concluded that isotretinoin can be used as an alternative to oral antibiotics in the treatment of rosacea subtype II and III [28].

\section{Lichen planus}

In a review of literature on the safety and effectiveness of topical retinoids in oral lichen planus patients. Sixteen studies were reviewed covering a total of 280 patients diagnosed with oral lichen planus who were treated with various classes of retinoids. The 
review concluded that isotretinoin was the most frequently used retinoid. Most of the studies demonstrated clinical and histopathological efficacy of retinoids used in the treatment of oral lichen planus [29].

\section{Cutaneous T-cell lymphoma (CTCL)}

In 1999 the FDA approved bexarotene for the treatment of cutaneous T-cell lymphoma (CTCL) that is refractory to at least one systemic treatment. Bexarotene exerts its effects by binding to the retinoid X receptor (RXR), which leads to apoptosis of CTCL cell lines [30]. In a multi-centre study conducted by Hamada et al. (2019) to evaluate the efficacy, safety and tolerability of bexarotene over $24 \mathrm{w}$, in 10 Japanese adults with cutaneous T-cell lymphoma (CTCL), the objective response rate was 53.8\% [31]. Morita et al. (2020) studied the efficacy and safety of combination therapy with photochemotherapy and bexarotene in 25 Japanese patients diagnosed with cutaneous T-cell lymphoma (CTCL) over $24 \mathrm{w}$. The patients were treated with bexarotene $300 \mathrm{mg}$ and PUVA or narrow-band UVB. The results were reported using two different assessments: the modified Severity-Weighted Assessment Tool (mSWAT) and the Physician Global Assessment of Clinical Condition (PGA). The response was $80.0 \%$ (mSWAT) and $84.0 \%$ (PGA) [32].

\section{Kaposi sarcoma}

In a multicentre, randomized, double-blind, controlled study that was conducted over a period of $12 \mathrm{w}$ for 268 patients with cutaneous Kaposi sarcoma to evaluate the efficacy and safety of alitretinoin $0.1 \%$ gel, or matched vehicle with no active drug as control. The study results showed alitretinoin $0.1 \%$ gel was superior to placebo in treating cutaneous Kaposi sarcoma lesions and that alitretinoin was well tolerated by the patients and safe to use [33].

\section{CONCLUSION}

This review demonstrates that in a wide range of dermatological conditions, retinoids can be highly effective and well-tolerated when used with an effective pregnancy prevention program. It is believed that if these outcomes are more widely understood and patient concerns are properly addressed with factual information, many more patients would benefit from the group of medications.

\section{FUNDING}

No external funding

\section{AUTHORS CONTRIBUTIONS}

All authors contributed equally to perform the review and compile the submitted manuscript.

\section{CONFLICT OF INTERESTS}

The authors have no conflicts of interest to declare.

\section{REFERENCES}

1. Beckenbach L, Baron JM, Merk HF, Löffler H, Amann PM. Retinoid treatment of skin diseases. Eur J Dermatol 2015;25:384-91.

2. Science Direct. Available from: https://www. sciencedirect.com/topics/neuroscience/retinoic-acid-receptor [Last accessed on 23 Jul 2020].

3. Khalil S, Bardawil T, Stephan C, Darwiche N, Abbas O, Kibbi AG, et al. Retinoids: a journey from the molecular structures and mechanisms of action to clinical uses in dermatology and adverse effects. J Dermatol Treat 2017;28:684-96.

4. Archana J, Bhargavi V. Retinoids-an overview of clinical applications in dermatology. J Pharm Sci Res 2010;2:376-83.

5. Bremner JD, Shearer KD, McCaffery PJ. Retinoic acid and affective disorders: the evidence for an association. J Clin Psychiatry 2012;73:37-50.

6. Ludot M, Mouchabac S, Ferreri F. Inter-relationships between isotretinoin treatment and psychiatric disorders: depression, bipolar disorder, anxiety, psychosis and suicide risks. World J Psychiatry 2015;5:222.

7. Layton A, Dreno B, Gollnick H, Zouboulis C. A review of the European directive for prescribing systemic isotretinoin for acne vulgaris. J Eur Academy Dermatol Venereol 2006;20:773-6.
8. Layton A. The use of isotretinoin in acne. Dermato-Endocrinol 2009;1:162-9.

9. Increased interferon-[gamma], interleukin-12p40 and IL-8 production in Propionibacterium acnes-treated peripheral blood mononuclear cells from a patient with acne vulgaris (Report). J Dermatol Sci 2009;55:47.

10. Dispenza MC, Wolpert EB, Gilliland KL, Dai JP, Cong Z, Nelson $\mathrm{AM}$, et al. Systemic Isotretinoin therapy normalizes exaggerated TLR-2-mediated innate immune responses in acne patients. J Invest Dermatol 2012;132:2198-205.

11. Thielitz A, Abdel Naser MB, Fluhr JW, Zouboulis CC, Gollnick H. Topical retinoids in acne-an evidence-based overview. JDDG: J Deutschen Dermatol Gesellschaft 2008;6:1023-31.

12. Zaenglein AL, Pathy AL, Schlosser BJ, Alikhan A, Baldwin HE, Berson DS, et al. Guidelines of care for the management of acne vulgaris. J Am Acad Dermatol 2016;74:945-73. e33.

13. Leyden JJ, Tanghetti EA, Miller B, Ung M, Berson D, Lee J. Oncedaily tazarotene $0.1 \%$ gel versus once-daily tretinoin $0.1 \%$ microsponge gel for the treatment of facial acne vulgaris: a double-blind, randomized trial. Cutis 2002;69:12-9.

14. Cunliffe WJ, Danby FW, Dunlap F, Gold MH, Gratton D, Greenspan A. Randomised, controlled trial of the efficacy and safety of adapalene gel $0.1 \%$ and tretinoin cream $0.05 \%$ in patients with acne vulgaris. Eur J Dermatol 2002;12:350-4.

15. Carretero G, Ribera M, Belinchon I, Carrascosa JM, Puig L, Ferrandiz C, et al. Guidelines for the use of acitretin in psoriasis. Psoriasis group of the spanish academy of dermatology and venereology. Actas Dermosifiliogr 2013;104:598-616.

16. van de Kerkhof PCM. Update on retinoid therapy of psoriasis in: an update on the use of retinoids in dermatology. Dermatol Ther 2006;19:252-63.

17. Sommerburg C, Kietzmann H, Eichelberg D, Goos M, Heese A, Holzle E, et al. Acitretin in combination with PUVA: a randomized, double-blind placebo-controlled study in severe psoriasis. J European Academy Dermatol Venereol 1993;2:30817.

18. Tosti A, Ricotti C, Romanelli P, Cameli N, Piraccini BM. Evaluation of the efficacy of acitretin therapy for nail psoriasis. Arch Dermatol 2009;145:269-71.

19. Grønhøj Larsen F, Jakobsen P, Knudsen J, Weismann K, Kragballe K, Nielsen-Kudsk F. Conversion of acitretin to etretinate in psoriatic patients is influenced by ethanol. J Invest Dermatol 1993;100:623-7.

20. Rollman 0, Vahlquist A. Retinoid concentrations in the skin, serum and adipose tissue of patients treated with etretinate. $\mathrm{Br}$ J Dermatol 1983;109:439-47.

21. Dando TM, Wellington K. Topical tazarotene: a review of its use in the treatment of plaque psoriasis. Am J Clin Dermatol 2005;6:255-72.

22. Mason J, Mason AR, Cork MJ. Topical preparations for the treatment of psoriasis: a systematic review. Br J Dermatol 2002;146:351-64.

23. Blair H, Scott L. Alitretinoin: a review in severe chronic hand eczema. Drugs 2016;76:1271-9.

24. Ruzicka T, Lynde CW, Jemec GBE, Diepgen T, Berth-Jones J, Coenraads PJ, et al. Efficacy and safety of oral alitretinoin (9- cis retinoic acid) in patients with severe chronic hand eczema refractory to topical corticosteroids: results of a randomized, double-blind, placebo-controlled, multicentre trial. $\mathrm{Br} \mathrm{J}$ Dermatol 2008;158:808-17.

25. Zussman J, Ahdout J, Kim J. Vitamins and photoaging: Do scientific data support their use? J Am Acad Dermatol 2010;63:507-25.

26. Sorg 0, Kuenzli S, Kaya G, Saurat J. Proposed mechanisms of action for retinoid derivatives in the treatment of skin aging. J Cosmetic Dermatol 2005;4:237-44.

27. Altinyazar HC, Koca R, Tekin NS, Esturk E. Adapalene vs. metronidazole gel for the treatment of rosacea. Int J Dermatol 2005;44:252-5.

28. Gollnick H, Blume Peytavi U, Szabo EL, Meyer K, Hauptmann $\mathrm{P}$, Popp $\mathrm{G}$, et al. Systemic isotretinoin in the treatment of rosacea-doxycycline- and placebo-controlled, randomized 
clinical study. JDDG: J Deutschen Dermatol Gesellschaft 2010;8:505-14.

29. Petruzzi M, Lucchese A, Lajolo C, Campus G, Lauritano D, Serpico R. Topical retinoids in oral lichen planus treatment: an overview. Dermatology 2013;226:61-3.

30. Schadt CR. Topical and oral bexarotene. Dermatol Ther 2013;26:400-40.

31. Hamada T, Tokura Y, Sugaya M, Ohtsuka M, Tsuboi R, Nagatani $\mathrm{T}$, et al. Long-term efficacy and safety of bexarotene for
Japanese patients with cutaneous T-cell lymphoma: the results of a phase 2 study (B-1201. J Dermatol 2019;46:557-63.

32. Morita A, Tateishi C, Muramatsu S, Kubo R, Yonezawa E, Kato $\mathrm{H}_{\text {, }}$ et al. Efficacy and safety of bexarotene combined with photo (chemo) therapy for cutaneous T-cell lymphoma. J Dermatol 2020;47:443-51.

33. Walmsley WS, Northfelt ED, Melosky EB, Conant EM, Friedman Kien E, Wagner EB. Treatment of AIDS-related cutaneous kaposi's sarcoma with topical alitretinoin (9-cis-Retinoic Acid) gel. JAIDS J Acquired Immune Defic Syndromes 1999;22:235-46. 